\title{
EL CULTO MARIANO DEL ROSARIO DE POMPEYA
}

\author{
Eugenia Aloj \\ Università del Sannio, Benevento Italia \\ Anna Zollo \\ Universidad Quaroni (Sapienza, Roma)
}

Resumen: El trabajo enfrenta diferentes aspectos del nacimiento y evolución del turismo religioso en Pompeya. Son tomados en consideración los diferentes aspectos de la tipología de culto mariano de Pompeya, las varias expresiones de fe y la característica dominante de la devoción respecto a la Virgen del Rosario, definida por sus aspectos devocionales justamente "sacro popular".

Palabras clave: Pompeya, Rosario, turismo religioso, culto mariano, peregrinación.

Resumo: O culto mariano do Rosario de Pompeya

O traballo enfronta diferentes aspectos do nacemento e a evolución do turismo relixioso en Pompeya. Son tomados en consideración os diferentes aspectos da tipoloxía de culto mariano de Pompeya, as varias expresións de fe e a característica dominante da devoción respecto á Virxe do Rosario, definida polos seus aspectos devocionais xustamente "sacro popular".

Palabras clave: Pompeya, Rosario, turismo relixioso, culto mariano, peregrinación.

Abstract: The Marian cult of the Rosary of Pompeii

The paper addresses different aspects of the birth and development of religious tourism in Pompeii. It examines the different aspects of the Marian type cult in Pompeii, the various expressions of faith and the dominant nature of the devotion to the Virgin of the Rosary in Pompeii, justly defined by its devotional aspects as a "popular sacred" site.

Key words: Pompeii, Rosary, religious tourism, Marian cult, pilgrimage. 
El tema de la peregrinación es fundamental para el cristiano, ya que representa el viaje interior a través de la vida, camino tendiendo hacia la otra vida. La razón subyacente de este fenómeno se encuentra en su complejidad estructural y su variedad dinámica que también reúne las otras tipologías de manifestaciones religiosas y populares (F. D’Agostino, 2000), como la expresión concertada de la participación popular y la participación activa de la comunidad.

En la práctica de la peregrinación la correspondencia inmediata entre instancias psico-sociológicas y socio-estructurales desarrolla un papel determinante y está caracterizada por un simbolismo global ligado a la dinámica de rituales de los cultos diversos.

Con el término peregrinación se quiere indicar una práctica religiosa presente en casi todas las realidades religiosas de cada tiempo que consiste en ir colectiva o individualmente, a lugares considerados sedes de fuerza sobrenatural donde más fácilmente se puede encontrar ayuda divina, o se concreta la necesidad de superar la limitación del ser humano. La peregrinación es una práctica también en religiones no oficiales que en general son definidas como forma de "religiosidad popular".

El presente trabajo tiene como objetivo analizar los aspectos particulares de la peregrinación y de las actividades devocionales ligadas al culto mariano de Pompeya y considerar la transformación de las manifestaciones de culto en función de la evolución de costumbres y de la cultura de las clases sociales, sobre todo en la sociedad de la Campania.

\section{LAS DIFERENTES MANERAS DE PEREGRINACIÓN}

Ir en peregrinación no es simplemente visitar un lugar cualquiera para admirar los tesoros de naturaleza, arte e historia. Ir en peregrinación significa sobre todo salir de uno mismo para ir al encuentro de Dios allí donde Él se ha manifestado, allí donde la gracia divina se ha mostrado con particular esplendor y ha producido abundantes frutos de conversión y santidad entre los creyentes (Papa Benedicto XVI ). Bajo esta mirada la modalidad de las peregrinaciones individuales o colectivas han ido desenvolviéndose ligadas a las tradiciones populares locales y han tomado formas más cercanas al mismo sentir religioso y a la norma más exterior de la religiosidad y de la fe.

El verdadero peregrino va buscando el lugar sagrado, a diferencia del turista, aunque se sirve de los mismo medios de transporte, se alberga en los mismos hoteles y camina por las mismas calles, se mueve en un tiempo diferente y despierta a la gracia en la peregrinación, un hombre nuevo. El tiempo del peregrino es en realidad el tiempo de la memoria, el tiempo de la liturgia, en cambio el turista se mueve en el tiempo cósmico o el tiempo actual de sus intereses culturales.

La finalidad del peregrino era esencialmente una confirmación de la fe manifestada en un camino generalmente a pie, un camino de penitencia y obras de caridad; 
ahora esta práctica ha desaparecido y ha sido sustituida por una tipología más individualista y así ha comportado la participación singular de una peregrinación para pedir una gracia o agradecer la recibida, en vez de un momento de agregación colectiva, como confirmación de adhesión a un credo religioso. Por lo tanto la peregrinación ha pasado a tener una dimensión íntima y sugestiva. Ésta es la característica determinante en los peregrinos que van hoy a Pompeya.

\section{EL FENÓMENO DE LA VOCACIÓN TURÍSTICA DEL CULTO MARIANOA POMPEYA. EL AMBIENTE QUE LA RODEA Y LAANIMACIÓN PASTORAL}

Pompeya fue fundada por los osci, habitantes históricos del Sur de Italia. El territorio llano presentaba características óptimas para instalarse, al ser un territorio fácil de defender, óptimo para las actividades agrícolas por tratarse de terreno volcánico muy fértil. Pompeya fue edificada sobre una altura media de cerca de 30 metros sobre el nivel del mar, altura formada por una caída de lava en tiempos prehistóricos. Situada en la desembocadura del río Sarno, la ciudad estaba destinada a ser puerto de los centros de la Campania que no tenían una salida al mar. Su expansión tuvo lugar con la invasión romana.

El área se encuentra a los pies del Vesubio. Fue destruida por las diferentes coladas de lava, la más importante fue la que en el 79 d. C. sepultó la ciudad de Pompeya, y que fue descrita por Plinio el Joven en dos famosas cartas a Tácito. La característica de la ciudad de Pompeya es la presencia de dos fuertes atractivos: los culturales y los turísticos. Las excavaciones de la ciudad sepultada representan quizás un caso único, la realidad de una ciudad que, aunque muerta, vive de sus distintas expresiones sociales y económicamente representadas por restos todavía presentes en su rol cívico (las casas, tabernas, calles, casas de citas y testimoniadas por ricos frescos y pintadas); y el culto mariano representado por los sucesos históricos del encuentro del cuadro de la Santísima Virgen y de la construcción del Santuario y de las pías obras de

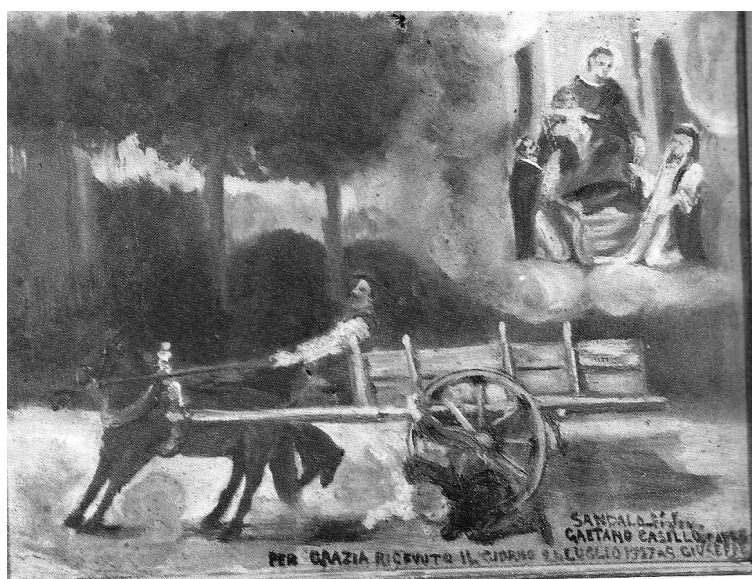
caridad relacionadas. 


\section{EVOLUCIÓN DEL CULTO MARIANO A POMPEYA}

El núcleo esencial y originario de la religiosidad unida al culto a María en Pompeya, surge de la manifestación y culto de la sociedad romana presente en aquellos lugares y estrechamente unidos a los caracteres típicos de una sociedad principalmente agrícola, que reconocía en los elementos y aspectos de las apariencias de la naturaleza las fuerzas que regulaban, influían y determinaban hechos humanos identificando una serie de divinidades a las cuales invocaban con solicitud especial para una buena cosecha en favor propio o de las variadas circunstancias de la vida. De ahí la especial atención dirigida por los habitantes de Pompeya en tiempos romanos a Hércules, Baco y Venus, citados por Marcial como dioses titulares de la región sepultada por el Vesubio. Particularmente practicado era el culto a la diosa Iside (Templo del siglo I a. C.) de Venere, expresión de la potencia de la naturaleza.

Tales prácticas comportaban el cumplir acciones particulares con el dios pagano, reguladas por determinadas y recíprocas obligaciones que consistían en una serie de ritos y fórmulas fijas y acciones realizadas a cambio de la ayuda divina. En el culto público, el responsable del sacrificio era un magistrado, en el culto privado el rol del sacrificante era reservado al pater familias por ser el depositario de la tradición recibida por los antepasados y que transmitía a sus hijos.

Las ceremonias de culto público estaban fijadas en un catálogo de fiestas distribuidas entre los meses del año y preveían ofrendas incruentas (libaciones) y sacrificios cruentos (víctimas animales).

Las libaciones comprendían varios productos: miel, vino, leche, trigo, los primeros frutos de la cosecha, cereales, uva, bollos de trigo triturado amasado con aceite y miel, ofrendas que tenían lugar también en el culto doméstico. Los sacrificios cruentos normalmente la inmolación de un buey, un carnero o un cerdo, pero también eran practicados sacrificios de caballos, perros, gallos y gallinas.

El culto privado presente en todas las circunstancias de la vida familiar se desarrollaba en momentos ordinarios y particulares como un nacimiento, la entrada en la edad adulta, el matrimonio, la muerte. Estos ritos se celebraban dentro de las paredes domésticas; para preservar las actividades agrícolas, los campos, bosques y bestias (ofrecimiento de vinos, de productos agrícolas, sacrificio de una cerda antes de la cosecha) la ceremonia se desenvolvía en el poder, al límite de la propiedad, al cruce que facilitaba la entrada. Diariamente el culto doméstico se practicaba delante de los altares siempre presente en cada casa y objeto de devoción votiva.

Numerosos son los restos encontrados que atestiguan estas actividades paganas. La vocación religiosa de la zona empieza a la llegada y conversión de Bartolo Longo al final del siglo XIX. 


\section{BARTOLO LONGO Y SUS OBRAS}

El culto mariano en Pompeya se debe a Bartolo Longo o, mejor, a su conversión ocurrida al inicio de 1870. Durante los primeros años de su juventud Bartolo Longo estuvo comprometido en grupo anticlericales, entró en una asociación laica llegando a ser "un sacerdote del espiritismo", en oposición a la Iglesia Católica. Pasado el tiempo esto lo llevó a una profunda crisis, una verdadera depresión psíquica y física (los ritos del satanismo exigían largos periodos de ayuno, pero afortunadamente no lo llevaron al suicidio). Su conversión fue debida al encuentro con el padre Radente de la orden de los dominicos. Fue este padre quien lo integró en la Tercera Orden de Santo Domingo acercándolo a la religión y al culto al Rosario.

El primero contacto de Bartolo Longo con los pompeyanos tuvo lugar en 1872 cuando llegó al Valle de Pompeya por motivos de trabajo. Constatando el estado de abandono de la zona decidió poner manos a la obra. Entonces se produjo el periodo de su conversión. Volvió algunos años a Pompeya para extender la devoción al Santo Rosario, y adquirió para la pequeña iglesia un cuadro que representaba a la Virgen del Rosario.

El 13 de febrero de 1876 el cuadro fue expuesto en la pequeña iglesia parroquial y desde aquel día la Virgen otorgó muchas gracias y milagros. La cantidad de peregrinos y devotos aumentó hasta el punto de tener que construir una iglesia más grande. Alrededor de esa construcción nació una ciudad mariana, la nueva Pompeya, con casas, hospitales, oficina de correos, telégrafos y hasta una estación ferroviaria.

\section{EL CULTO DEL ROSARIO}

La tradición del Rosario es muy antigua, aparece en el siglo XIII. Gracias al rezo del Rosario, bajo el pontificado de Pío V, el mundo occidental venció a las tropas turcas en la batalla naval de Lepanto.

La devoción del rezo del Rosario, llamado también Salterio, tuvo gran extensión por la facilidad para rezarlo; fue llamado el Evangelio de los pobres porque permitía rezar y al mismo tiempo meditar los misterios cristianos sin necesidad de leer un texto. El culto al Rosario se difundió después de las apariciones de Lourdes de 1858, cuando la Virgen encomendó la práctica de esta devoción. Nació como forma alternativa del breviario para los monjes que no sabían leer

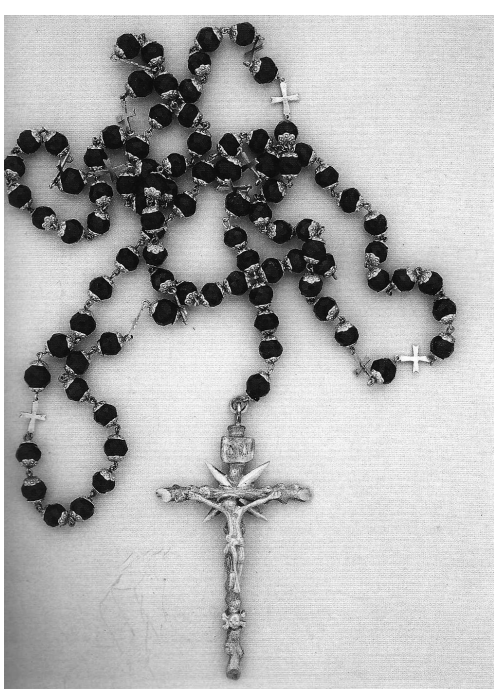


pues tenían que rezar en algunas horas del día; así su modo de observar la liturgia de las horas estaba cumplida, es decir, con el rezo del "Salterio Mariano" que consistía en 150 Ave Marias en tres partes y en tres momentos del día.

Pompeya es la sede del más grande santuario italiano dedicado a Nuestra Señora del Rosario en la que se venera una famosísima imagen pintada en el siglo XVIII. Muy apreciada y rezada es también la famosa Súplica a la Virgen de Pompeya, escrita por el Beato Bartolo Longo, gran propagador del culto y de la imagen mariana de la ciudad campana.

\section{EL SANTO ROSARIO DE NUESTRA SEÑORA DE POMPEYA}

El culto a María se expresa sobre todo a través del Rosario, no como una oración cualquiera sino como fundamento de una búsqueda particular de la intercesión de la Virgen. El Rosario tiene en sí mismo un valor intrínseco, el de la conversión, del espíritu de oración y de las obras de caridad.

La palabra "rosario" deriva de un uso del medioevo que consistía en poner una corona de rosas sobre la estatua de la Virgen; esas rosas eran símbolo de las oraciones "bellas" y "perfumadas" hechas a Maria. Así nació la idea de utilizar una cadena de granos para guiar la meditación (de la corona rosario). La corona del rosario se compone de una serie de granos, una medalla y una cruz.

El rosario tiene un valor cristológico. En el Rosario se repiten 150 Ave Marías que recuerdan el número de salmos del Antiguo Testamento. Por esto es correcto decir que el Rosario es amparo y refugio de los cristianos que lo rezan con sincera devoción y amor. El Rosario tiene una fuerza purificadora y tranquilizante del alma precisamente por su continua repetición.

Los misterios contemplativos en el rezo del Rosario son 15, cinco gozosos, cinco dolorosos, cinco gloriosos. A estos en el 2002 el Papa Juan Pablo II añadió los cinco misterios de la Luz, que meditan particularmente algunos momentos significativos de la vida pública de Jesús Cristo.

Antiguamente, el primer domingo de octubre en las iglesias, los patios y casas se rezaba una introducción al Rosario y se llamaba "Cien cruces y Cien Ave Marías" con clara referencia a las cruces de la Liga Santa y en sufragio de las almas de

Il Rosario benedetto di Maria; Catena dolce che ci rannodi a Dio; Vincolo di amore che ci unisci agli Angeli; Torre di salvezza negli assalti d'inferno; Porto sicuro nel comune naufragio, noi non ti lasceremo mai più. Tu ci sarai conforto nell'ora di agonia; a te l'ultimo bacio della vita che si spegne. E l'ultimo accento delle smorte labbra sarà il nome vostro soave, Regina del Rosario della Valle di Pompei, o Madre nostra cara, o unico Rifugio dei peccatori, o sovrana Consolatrice dei mesti. Siate ovunque benedetta, oggi e sempre, in terra e in cielo. Così sia. 
los cristianos fallecidos en la Batalla de Lepanto, más de siete mil quinientos contra más de treinta mil turcos.

\section{LA SÚPLICA}

La Súplica a la Reina del Rosario de Pompeya fue escrita en 1883 por Bartolo Longo, con el título "Un acto de amor a la Virgen". Es rezada solemnemente dos veces al año, a las 12 horas del 8 de mayo y el primer domingo de octubre, atrayendo a miles de peregrinos provenientes de toda Italia y del extranjero, que en estas ocasiones se reúnen delante de la fachada del santuario para rezar todos unidos.

La Súplica fue compuesta por Bartolo Longo como adhesión a la invitación que, en su primera encíclica del Rosario, el Papa León XIII había hecho a los católicos como empeño espiritual para el remedio de los males de la sociedad. El texto de la súplica, que en el tiempo ha tenido varios retoques hasta llegar a la actual formulación, es profundamente atrayente por su lírica musical. Se caracteriza por una coral única y unificante. Entre todas las oraciones compuestas por autores italianos es la más famosa en el mundo. Ha sido traducida a una decena de lenguas: del inglés al ruso, del armenio al chino, del urdu al maltés, al tamil, etc. La Súplica se recita igualmente en la iglesia o en casa, a la misma hora, el mismo día y en todo el mundo.

En Pompeya la celebración está precedida por la Santa Misa, que se celebra delante de la fachada del santuario. Durante el rito, presidido por obispos y cardenales, se reza por la paz, el desarrollo de los pueblos, por la superación de la injusticia social, por la familia.

Se recuerda siempre la vida y la extraordinaria obra realizada por el Beato Bartolo Longo en Pompeya. Para favorecer la participación de los peregrinos se instalan grandes pantallas. En tiempos recientes la súplica se trasmite en directo por televisión y radio a nivel nacional e internacional.

La devoción del Santo Rosario y el rezo de la súplica representan una de la más típicas e importantes manifestaciones del culto mariano de Pompeya. No obstante la evolución de los tiempos caracterizada por la diferente urbanística de los lugares realizada para contener mas peregrinos, lamentablemente muy mercantilizada, el espíritu religioso y popular del culto mariano no ha cambiado y se desenvuelve en estas dos fundamentales prácticas religiosas.

Característica fundamental del culto mariano de Pompeya para los campanos y sobre todo para los napolitanos es la familiaridad. Con esta terminología se indica la relación particular entre los napolitanos y la Virgen del Rosario, considerando a la Virgen como a San Jenaro un familiar a quien suplicar sea en los momentos de necesidad como en una relación de devoción afectuosa. 
Esta peculiaridad de culto procede muy probablemente de la costumbre del ciudadano romano que establecía entre los muros domésticos una relación particular con los Lares (Lari) familiares. También esta práctica desciende de las costumbres de los antiguos romanos: la devoción a Nuestra Señora de Pompeya es parecida al culto mariano de los Lares, los lararia se colocaban en la cocina, lugar del hogar doméstico, junto a Vesta, los Lares aseguraban continuidad y bienestar a la entera familia.

\section{SALVE O REGINA.}

Salve O Regina, Madre di misericordia, vita e dolcezza e speranza nostra, salve. A te ricorriamo esuli figli di Eva, a te sospiriamo gementi e piangenti in questa valle di lacrime. Orsù dunque avvocata nostra, volgi a noi, quegli occhi tuoi misericordiosi e mostraci dopo questo esilio, Gesù, il frutto benedetto del tuo seno. O clemente, o pia, o dolce Vergine Maria

\section{LOS EXVOTOS}

Los exvotos que testimonian la dimensión hasta internacional del culto mariano y su viva actualidad todavía hoy, y también la importancia social del mismo, está representada por prácticas de los exvotos de la colección histórico artística de los mismos. Los exvotos que testimonian la relación entre el fieles y la divinidad, cuentan el éxito de la intervención divina siempre real y concreta de aquel que lleva el exvoto. Su afirmación se debe a los decretos de Urbano XVIII. El fenómeno de los dones votivos está todavía vivo aunque asume con frecuencia formas distintas con respeto del pasado: en el momento actual la fotografía y la necesidad de documentar son actos fundamentales.

Los exvotos tienen un lenguaje cultural y religiosamente específico que radica en la compleja tradición de la piedad popular; quieren manifestar a través de la invocación de la Virgen una repuesta de fe, de reconocimiento, de gracia.

A las evaluaciones religiosas, que son fundamentales para los exvotos, se añaden otras mirando el ambiente, las costumbres y el paisaje. Por lo que se puede afirmar que los exvotos pueden ser una especie de libro en que pueden leerse tantas noticias útiles a la religión y la educación, pero sobre todo los usos y costumbres de una religiosidad cargada de valor meridiano o de un modo de ver la religión con un sentimiento particular de vecindad y familiaridad.

Desde los tiempo más antiguos en todos los pueblos, el exvoto expresa la petición de ayuda o agradecimiento a través no solo de las palabras sino con regalos duraderos. Los exvotos pueden ser de diferentes formas, pinturas, cartas, cabellos, vestidos y objetos de oro.

En las pinturas el concepto es expresado con la sigla "VFGA" (votum fecit, gratiam, accepit) voto, hecho, gracia, recibida. Por lo tanto los exvotos no son solo testimonio de gracias recibidas, tienen también la necesidad de visibilidad perpetua 
del sentimiento popular con el fin de enfatizar un milagro. Los materiales empleados para la realización son madera, láminas de hierro y desde la segunda mitad del siglo noveno masonitas y cartulinas. Representan escenas de gracias recibidas como consecuencia de accidentes agrícolas, naufragios, enfermedades, sucesos bélicos, rayos, accidentes en el trabajo. El dibujo es simple, a veces más bien ordinario. Encima está representado el santo, la Virgen... según el modelo tradicional de la imagen de culto.

Entre los varios testimonios los hay de niños que han recibido la gracia y por ello hacen en ofrecimiento a la Virgen una estatua de cera o de plata de la misma altura y peso; y aquellos de mujeres que componen sobre el lienzo los cabellos cortados por el voto.

Generalmente los exvotos no son expresión creativa del devoto sino fruto del trabajo de maestros artesanos que con su genialidad y maestría buscan re-presentar los sentimientos interiores de los solicitantes. Antiguamente era posible distinguir dos tipos de exvotos: los de la nobleza y la alta burguesía, y los de la gente común. En el primer caso se trataba de cuadros realizados por artistas de fama que representaban las escenas de la gracia recibida, en el segundo caso en cambio objetos o mechones de cabellos.

\section{LAS OBRAS DE LA FE}

El movimiento deseado por Bartolo Longo, que comenzó en el período industrial, sigue las huellas de Don Bosco en Turín, donde la práctica religiosa ha asumido un papel social para recuperar y prestar apoyo a las clases sociales más pobres, dando apoyo no sólo económico, sino a través de la profesionalización.

Para desarrollar la obra de la redención y la devoción en las comunidades de Pompeya, Bartolo Longo hizo diferentes obras de caridad. En 1887 fundó un orfanato para niñas huérfanas, en 1891 otro para niños, y en 1897 el Instituto de las Hijas del Rosario de Pompeya para la educación de niñas y niños. También un Instituto para los hijos de los encarcelados y otro para las hijas de los mismos, la Congregación femenina de las Hermanas Dominicanas Hijas del Santo Rosario de Pompeya, las Casas Obreras para los dependientes de la imprenta y la encuadernación, las oficinas para la escuela de arte y oficios transformadas sucesivamente en institutos profesionales. 

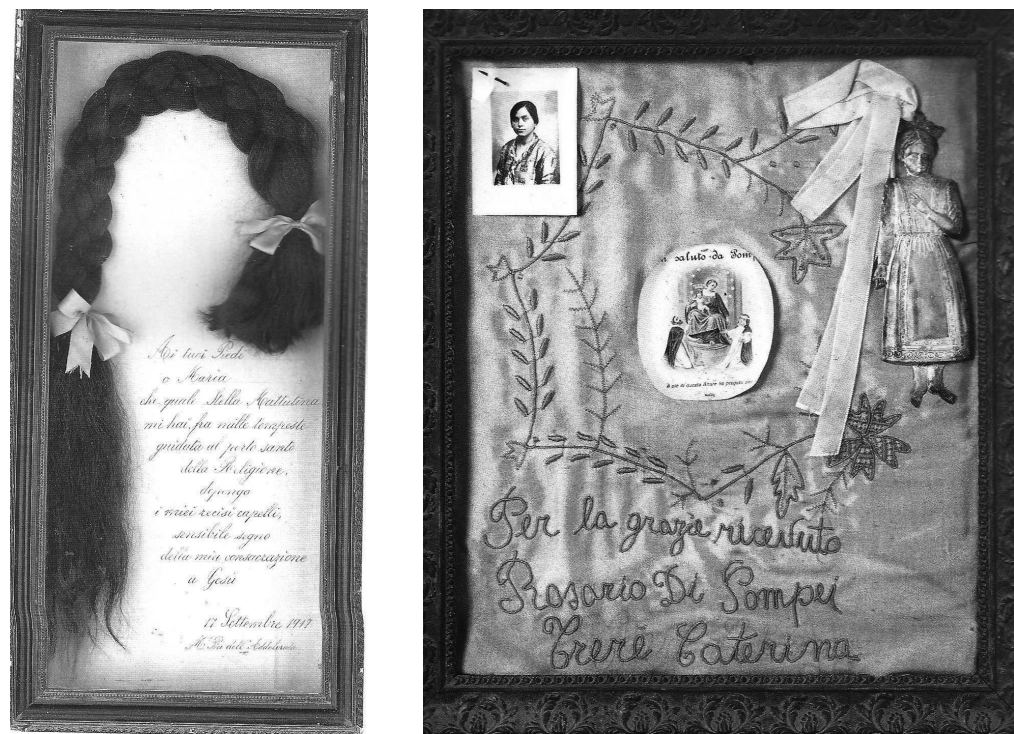

\section{TERRITORIALIDAD Y EXTRATERRITORIALIDAD DEL CULTO DEL SANTO ROSARIO DE POMPEYA}

Rezar a la Virgen de Pompeya significa para la gente del sur de Italia o de la Campania expresar su propia identidad de hijos que imploran a la Virgen su intercesión.

Varias son las acciones que se llevan a cabo. Muchos llegan a la ciudad mariana a pie, como la costumbre de la peregrinación del pueblo de Pignataro, que el día anterior a la súplica continúan el camino de fe empezado por sus padres para agradecer a la Nuestra Señora de Pompeya el haber escuchado sus súplicas. Cada año se va a pie a Pompeya y después de una vigilia de oración se reza la súplica con la certeza de que la Virgen escuchará las oraciones .

Las diversas acciones de devoción han sido muy diferentes en el tiempo, por tradición popular se regalaba una vez a los recién nacidos, adornos con joyas de oro y la imagen de la Virgen de Pompeya en particular en ocasión del bautismo. La cadenita recibida como don con la sagrada imagen de la Virgen de Pompeya tenía que acompañar al recién nacido toda su vida en una mezcla de devoción y superstición.

Además en cada casa se procuraba poner en la puerta de entrada un pequeño cuadro representando a la Virgen de Pompeya y las madres saludaban al hijo, cuando salía de casa con la frase "Ca Maronn t'accumpagn quant pass daj" "que la Virgen siga contigo en todos tus pasos", poniendo en las manos de la Virgen la vida del propio hijo. Esta costumbre de vida de la población campana y napolitana en par- 
ticular el sentir religioso y de expresión de la fe como un momento de la propia vida familiar. Estas ocasiones son también el testimonio de la particularidad del culto de San Jenaro, patrono de la Ciudad de Nápoles. Los habitantes de la Campania tienen un fuerte sentido de devoción por el culto a las reliquias de San Jenaro y la licuefacción de la Sangre del Santo que es auspicio de prosperidad para el pueblo napolitano.

\section{RELACIÓN CON LOS INMIGRANTES}

La devoción a la Virgen de Pompeya está extendida en todo el mundo gracias sobre todo a los emigrantes, a los cuales antes de embarcarse en el puerto de Nápoles, Bartolo Longo entregaba cuadros de la Virgen, rosarios y libros de oraciones. En el mundo han nacido así muchísimas iglesias, parroquias y santuarios dedicados a la Virgen de Pompeya.

En los Estados Unidos hay diez iglesias dedicados a la Virgen de Pompeya: Nueva York, Chicago, Providence, Lancaster, etc. Otras tantas hay en Canadá: en Montreal, en Vancouver, etc. Se encuentran también en Argentina, Brasil, Venezuela y Uruguay y en todas se organizan numerosas actividades para promover el culto y la devoción a la Virgen. Contemporáneamente en diversas partes del planeta, de Nueva York a Buenos Aires, de Toronto a Sydney, Johannesburgo a Caracas, millones de fieles se encuentran juntos para rezar la súplica a la Virgen del Rosario en las fecha del 8 de mayo y el primer domingo de octubre.

\section{CONCLUSIONES}

El culto mariano es el tipo de vocación religiosa más percibida en la Campania, es expresión del sentimiento sacro popular. Esto es explicable según Canzanella pues en Campania el elemento femenino ha sido siempre mayormente objeto de culto respecto al masculino dado que el sustrato social y popular campano es "falsamente patriarcal." [C. Canzanella], pero al mismo tiempo es predominante la estructura familiar.

En la tradición popular campana son siete las hermanas a las cuales son dedicadas las fiestas y los otros tipos de prácticas religiosas colectivas, esto en un arco temporal bastante corto, de febrero a septiembre.

Numerosas son las imágenes de la Virgen veneradas en Campania, algunas llevan el nombre de los lugares con los cuales se relacionan (Virgen de Pompeya, Virgen de Montevirgen, etc.), otras de una calidad o objeto atribuido a ellas (Virgen de la Paz, Virgen del Castillo, Virgen de las gallinas, etc).

La difusión tan amplia e intensa del culto mariano en particular en la zona vesubiana, es una forma de devoción de tipo intimista y forma de culto que asume una dimensión particular que encuentra en las fiestas y en las peregrinaciones sus formas características de expresión. Hoy con la evolución cultural ocurrida en Italia en los 
últimos decenios, es más forma de devocionismo que de verdadera y propia devoción. Parcialmente se oponen a esta característica del culto las clases sociales más populares y que provienen de ambientes estrechamente rurales.

Por otro lado la ruralidad es una de los componentes de la población vesubiana y si vamos al nacimiento mismo del culto (1874) se ve como en el Valle de Pompeya fueron en un tiempo presentes los factores predominantes de una comunidad de campesinos.

\section{BIBLIOGRAFÍA}

BAUMAN, Z.(1995): Da pellegrino a turista, In rassegna italiana di sociologia XXXVI, n.1.

CARRIER, H,; PIN, E. (1967): Saggio di sociologia religiosa, A.V.E. Roma.

CAZENEUVE, I. (1968): Sociologia del rito, Milano, il Saggiatore.

CARPICECI, A C. (2007): Oggi e com'era 2000 anni fa, Bonechi-Edizioni Il Turismo Pompei.

D’AGOSTINO, F.; VESPASIANO F. (2000): L'icona della sofferenza, Roma, Studium.

DE SANDRE, P. (1967): Sociologia della religione, Roma A.V.E.

FERRAROTTI, F.; CIPRIANI R., (1974): Sociologia del fenomeno religioso, Roma, Bulzoni.

GENNARO, A. (1980): Il beato Bartolo Longo, Ist. profess. grafico Bartolo Longo, Pompei.

MALDONADO, L. (1982): Natura y funcion del Santuario, Vitoria.

TURNER, V. (1976): La foresta dei simboli, Brescia, Morcelliana.

VAN GENNEPT, A. (1969): I riti di passaggio, Torino, Boringhieri Editore. 